\title{
OVERVIEW OF SINGLE WALLED CARBON NANOTUBES \& TOXICITY PROFILE
}

\author{
Vijayalakshmi $V^{1}$, PriyaAshrit ${ }^{2}$, BinduSadanandan ${ }^{3}$ \\ ${ }^{I}$ Department of Biotechnology, M S Ramaiah Institute of Technology, MSR Nagar, MSRIT Post, Mathikere, \\ Bangalore-560054 \\ ${ }^{2}$ Department of Biotechnology, M S Ramaiah Institute of Technology, MSR Nagar, MSRIT Post, Mathikere, \\ Bangalore-560054 \\ ${ }^{3}$ Department of Biotechnology, M S Ramaiah Institute of Technology, MSR Nagar, MSRIT Post, Mathikere, \\ Bangalore-560054
}

\begin{abstract}
Carbon nanotubes (CNTs) have attracted the fancy of many scientists in the recent decade. They are produced on a large scale due to their demand of being strong and light weight. Single Walled Carbon Nanotubes (SWCNTs)are an important class of CNTs. SWCNTs structurally resemble graphite sheets which are rolled up with usually one end capped. The major strengths of SWCNTs are small size, larger length, high permeability, tensile strength, electrical \& mechanical properties. Major methods of synthesis of SWCNTs are arc discharge, laser ablation and chemical vapor deposition (CVD). SWCNTs have potential applications in many fields such as medicine, industry, research, and computers. However, there are many studies that implicate the toxicity of SWCNT. To evaluate the toxicity of SWCNTs they have been studied both in vitro and in vivo. Toxicity of SWCNTs can be reduced by functionalization of the SWCNTs. In this review we mainly provide an overview of CNTs especially SWCNT \& its toxicity.
\end{abstract}

Keywords: Carbon Nanotubes, Single Walled Carbon Nanotubes, Toxicity, Synthesis

\section{INTRODUCTION}

\subsection{Carbon Nanotubes (CNTs)}

Various sized particles surround us on an everyday basis, the tiniest of the particles which is visible to the naked eye to the ones which are not visible. Many of such particles are the ones which causes various diseases when entered into the body. Some of them are removed by the defence system in our bodies while the others go past these defences and enter the body causing discomfort \& diseases (Buzeaet al., 2007).

Nanomaterials have been used extensively in the recent era in research, medicine \& industries (Bang et al., 2011; Hardaset al., 2012; Yang et al., 2010). Nanomaterials such as Nanotubes, Nanoparticles, Nanocomposites are the next generation materials used for the manufacture of faster computers, drug discover and sensitive sensors (Asmatulu, 2011).

Carbon Nanotubes (CNTs) have been used from the past decades \& also is emerging as an important class of nanomaterials (Bang et al., 2011; Ravichandranet al., 2010). Carbon nanotubes were discovered and first characterized in 1991 by Iijima from NEC laboratories, Japan (Iijima, 1991).CNTs have gained tremendous attention as promising nanomaterials, owing to their distinct characteristics such as small size, strength, conductivity, high surface area, possibility of conjugation with therapeutics including small molecules \& biologics (Wong et al.,2013; Bang et al.,
2011). However, CNTs are considered toxic for the environmental as well as human health (Bang et al., 2011).

The conductivity of CNT is determined by its chirality, tube diameter \& number of graphene walls. The graphene sheet of carbon atoms are arranged in 3 different chirality: armchair, chiral \& zigzag (Bareket-Keren\&Hanein, 2013). Nanotubes of the type $(n, 0) \theta=0^{\circ}$ are called zigzag tubes. Nanotubes of the type $(n, n) \quad \theta=30^{\circ}$ are called armchair tubes. Both zigzag and armchair nanotubes are achiral tubes, in contrast with general $(n, m \# n \# 0)$ chiral tubes (Charlieret al., 2007; Dai H, 2002).

\subsection{Types of Carbon Nanotubes}

CNTs come in two different forms, Single Walled Carbon Nanotubes (SWCNTs) \& Multi Walled Carbon Nanotubes (MWCNTs) (Bang et al., 2011; Sargent et al., 2014; Berhanuet al., 2009).SWCNTs are simple with diameter ranging from 0.4 to $2.5 \mathrm{~nm}$ and length up to few millimetres. MWCNTs are a set of coaxially organized SWCNTs with 2$100 \mathrm{~nm}$ diameter and length varying up to several hundred micrometres (Bareket-Keren\&Hanein, 2013).

\subsection{Synthesis of Single Walled Carbon Nanotubes}

Single walled carbon nanotubes can be synthesized by many methods (Dhai, 2001). Arc-discharge, laser ablation involve carbon vaporization at high temperatures and employs solid state carbon precursors. CVD utilizes hydrocarbon gases as sources for carbon atoms (Dai, 2002). 
SWNTs were produced from a low cost catalytic decomposition of hydrocarbons using an improved floating catalyst method, which yielded SWCNTs of larger diameters and are self-organized into ropes. The addition of thiophene was found to be effective in promoting the growth of SWNTs (Cheng et al., 1998). SWCNTs were synthesised by CVD method in which water enhanced the activity and lifetime of catalyst (Hataet al., 2004).

There is also studied which have used alcohol as a carbon source to synthesize SWCNTs by chemical vapour deposition method at low temperatures (Maruyama et al., 2002).

SWCNTs can also be produced by zipping effect of liquids to draw tubes together. This helps in fabricate the solids in numerous shapes and structures by retaining the individual property (Futaba et al., 2006).

\subsection{Applications of Single Walled Carbon Nanotubes}

SWCNTs are been widely used many fields such as industry, medicine, research, computer, aerospace and biomedical (Onget al., 2016).

SWCNTs are well suited for neuronal electrical interfacing owing to their large surface area, electrical \& mechanical properties and their support as an excellent neuronal adhesion (Bareket-Keren\&Hanein, 2013).

SWCNTs have been used in the protein studies especially enzyme activities to study the loss of structure and catalytic activity. Some of the enzymes such as horse radish peroxidase, chicken egg white lysosome on SWCNTs retain their structure \& activity even under denaturing conditions (Saptarshiet al., 2013).

SWCNT has covered through many other applications such as in vivo delivery of drugs, proteins, peptides and nucleic acids, in vivo tumour imagingand tumour targeting of SWCNTs as an anti-neoplastic treatment (Schipperet al., 2008).

Highly purified SWCNT can exhibit good antimicrobial activity (Kang et al., 2007).

Some of the limitations of SWCNTs are nanotube cost, processing and assembly difficulties and polydispersity in nanotube type (Baughman et al., 2002).

\subsection{Toxicity of Single Walled Carbon Nanotubes}

Cytotoxicity studies revealed that toxicity of SWCNTs in vitro and in vivo is more when compared to MWCNTs and other forms of CNTs. Cytotoxicity of SWCNTs may be due to their geometry and surface chemistries(Poma\& Di Giorgio, 2008).

CNTs having high length and diameter gives them an appearance as a fibre, hence, they are compared to asbestos
(Berhanuet al., 2009). CNTs such as SWCNTs may cause asbestos like pathology in lung \& mesothelium. CNTs in the form of long chains have greater propensity to inflammation $\&$ fibrosis than long chained asbestos (Donaldson et al., 2010).

Nanoparticle aerosol exposure is increasing in the modern society due to the advancement of nanotechnology (LeBlanc et al., 2010).Studies conducted till date have shown that SWCNTs do not show any carcinogenic activity, however, toxicity studies of these materials are less and they have a potential to produce Reaction Oxygen Species (ROS) (Tsuda, 2010). Toxicity \& carcinogenicity of Carbon Nanotubes are of a concern, despite their desired structure, since they are very stable and lead to continuous inflammation when deposited in tissues (Totsuka et al., 2009).

\section{IN VITRO TOXICITY}

There are studies which revel that SWCNTs cause acute pulmonary inflammation \& chromic fibrosis (Lam et al., 2004; Warheitet al., 2004). Pulmonary deposition of SWCNTs results in the release of inflammatory mediators activated blood cells \&Thrombogenic proteins which may induce endothelial dysfunction (Erdelyet al., 2008).

In vitro studies were conducted to study the effect of SWCNTs on human macrophage like cells. It was observed that macrophage was uptaken by SWCNT to form nanoparticle-loaded macrophages (Poma\& Di Giorgio, 2008).

There is also a possibility of translocation of carbon nanotubes such as SWCNTs when used in lower diameters. (Pacurariet al., 2008) Wang et al., 2004 revealed the presence of functionalized SWCNT $\mathrm{I}_{125}$ in stomach, kidneys and bone. There are also studies showing the difference in biokinetics between modified and unmodified SWCNTs. Modified SWCNTs were found to be in the blood and tissues whereas, unmodified SWCNTs were found only in liver after 24h. (Elgrabliet al., 2008)

SWCNTs when fused with plasma membrane have showed cell damage through lipid peroxidation and oxidative stress (Manna \& Ramesh, 2005; Poma\& Di Giorgio, 2008).

In a study by Davorenet al., 2007, with human lung cell line A549, it was observed that SWCNT showed very low acute toxicity and also alamar blue $(\mathrm{AB})$ assay was found to be the most sensitive and reproducible assay among the different cytotoxicity assays.

Exposure of SWCNT on the skin causes dermal toxicity. A study showed that topical exposure to un-purifiedSWCNT, induced free radical generation, oxidative stress, and inflammation (Murray et al., 2009).In vitro studies on the human dermal fibroblasts (HDF) showed that as the sidewall functionalization increases the toxicity to SWCNT decreases (Sayeset al., 2006). 
Studies by Manna et al., 2005 showed that SWCNTs induced toxicity in HaCaT cells. Reaction Oxygen Species (ROS) was also measured for a dose dependant treatment. ROS production of SWCNT increased as the dose increased in $\mathrm{HaCaT}$ cells.

\section{IN VIVO TOXICITY}

In a study by Poland et al., 2008, showed carbon nanotubes when introduced in the abdominal cavity of mice it showed asbestos like pathogenicity (Stimers, 2008).

SWCNT induced dose-dependent epithelioid granulomas. It was studied that with higher dose of SWCNT toxicity increased causing death of the mice. Peribronchial inflammation and necrosis was observed in lungs of some animals that had extended into the alveolar septa. This is aserious occupational health hazard in chronic inhalation exposure (Lam et al., 2004).

SWCNT not only affects the human but also the aquatic life. Toxicity studies have been done on rainbow trout. SWCNTs are basically respiratory toxicant in trout and showed no variations in the oxidative stress and osmoregulatory disturbances, but cellular pathologies raise concerns about cell cycle defects \& neurotoxicity (Smith et al., 2007).

Toxicity of SWCNTs was observed within 10 to 15 days of exposure to the mice. But functionalization has reduced the toxicity of SWCNTs to a greater extent. Schipperet al., 2008 have studied the functionalized SWCNTs toxicity in the bloodstream of injected mice. They revealed that there was no sign of toxicity even until 4 months of exposure, only changes which was seen was age related. Yang et al., 2008 also proved very low toxicity of SWCNTs on the mice when accumulated for longer duration of time. Very slight inflammation of organs was observed with no apotosis.

\section{CONCLUSION}

CNTs are an important class ofnanomaterials having wide properties and used in wide range of applications. CNTs can be basically grouped into SWCNTs and MWCNTs based on their conductivity. There are three basic methods of synthesis of SWCNTs viz. arc discharge, laser ablation and chemical vapordeposition (CVD). CVD is the most accepted and used method. Researchers are trying to improvise on this method so as to produce large quantities of SWCNT with lesser diameter and larger length. With the widespread applications of SWCNTs there is a need for its production on a large scale. It has however been provenin vitro and in vivo that SWCNTs are toxic especially to humans. There are also studies which prove that the toxicity of SWCNTs is dose dependant. Hence SWCNTs are functionalized to reduce their toxicity. Though SWCNTs are being used commercially for many applications, the upcoming scope is in the areas of drug delivery and in antimicrobial therapy.

\section{ACKNOWLEDGMENT}

The authors wish to thank the Management \&Principal, M.S Ramaiah Institute of Technology (MSRIT), Bengaluru560054 , for their constant encouragement \& support. They also wish to thank the HOD, Department of Biotechnology, MSRIT for kind support \& encouragement.

\section{REFERENCES}

[1] Asmatulu R (2011) Toxicity of Nanomaterials and Recent Developments in Lung Disease. Bronchitis, Dr. Ignacio Martan-Loeches (Ed.), ISBN: 978-953307-889-2, InTech.

[2] Bang J, Yeyeodu S, Gilyazova N, Witherspoon S, Ibeanu G (2011) Effects of Carbon Nanotubes on a Neuronal Cell Model In vitro. Atlas J Biol. 1(3):7077.

[3] Bareket-Keren L and Hanein Y (2013) Carbon Nanotube-Based Multi Electrode Arrays for Neuronal Interfacing: Progress and Prospects. Front. Neural Circuits 6:122. doi: 10.3389/fncir.2012.00122.

[4] Baughman RH, Zakhidov AA, de Heer WA (2002) Carbon Nanotubes--the Route Toward Applications. Sci. 297(5582):787-792.

[5] Berhanu D, Dybowska A, Misra SK, Stanley CJ, Ruenraroengsak P, Boccaccini AR, Tetley TD, Luoma SN, Plant JA, Valsami-Jones E (2009) Characterization of Carbon Nanotubes in the Context of Toxicity Studies. Environ. Health 8(1):S3.

[6] Buzea C, Pacheco II, Robbie K (2007) Nanomaterials and Nanoparticles: Sources and Toxicity. Biointerphases 2(4):MR17-71.

[7] Charlier JC, Blasé X, Roche S (2007) Electronic and transport properties of nanotubes. Rev. Mod. Phys. 79(2): 677-732.

[8] Cheng HM, Li F, Su G, Pan HY, He LL, Sun X, Dresselhaus MS (1998) Large-scale and low-cost synthesis of single-walled carbon nanotubes by the catalytic pyrolysis of hydrocarbons. Appl. Phys. Lett. $72: 3282$.

[9] Chou CC, Hsiao HY, Hong QS, Chen CH, Peng YW, Chen HW, Yang PC (2008) Single-Walled Carbon Nanotubes can Induce Pulmonary Injury in Mouse Model. Nano Lett. 8:437-445.

[10] Dai H (2002) Carbon Nanotubes: Synthesis,Integration, and Properties. Acc. Chem. Res. 35, 1035-1044.

[11] Dai H (2001) Nanotube Growth and Characterization. Carbon Nanotubes; Springer 29-53.

[12] Donaldson K, Murphy FA, Duffin R, Poland CA (2010) Asbestos, Carbon Nanotubes and the Pleural Mesothelium: A Review of the Hypothesis Regarding the Role of Long Fibre Retention in the Parietal Pleura, Inflammation \& Mesothelioma. Part. FibreToxicol.7:5.

[13] Davoren M, Herzog E, Casey A, Cottineau B, Chambers G, Byrne HJ, Lyng FM (2007) In Vitro Toxicity Evaluation of Single Walled Carbon Nanotubes on Human A549 Lung Cells. Toxicol.In Vitro. 21(3):438-448. 
[14] Elgrabli D, Floriani M, Abella-Gallart S, Meunier L, Gamez C, Delalain P, Rogerieux F, Boczkowski J, Lacroix G (2008) Biodistribution and Clearance od Instilled Carbon Nanotubes in Rat Lung. Part.Fibre 5:20.

[15] Erdely A, Hulderman T, Salmen R, Liston A, ZeidlerErdely PC, Schwegler-Berry D, Castranova V, Koyama S, Kim YA, Endo M, Simeonova PP (2008) Cross-Talk Between Lung and Systemic Circulation During Carbon Nanotube Respiratory Exposure. Potential Biomarkers. Nano Lett. 9(1):36-43.

[16] Futaba DN, Hata K, Yamada T, Hiraoka T, Hayamizu Y, Kakudate Y, Tanaike O, Hatori H, Yumura M, Iijima S (2006) Shape-Engineerable and Highly Densely Packed Single-Walled Carbon Nanotubes and their Application as Super-Capacitor Electrodes. Nat. Mat. 5:987 - 994

[17] Hardas SS, Sultana R, Warrier G, Dan M, Florence RL, Wu P, Grulke EA, Tseng MT, Unrine JM, Graham UM, Yokel RA, Butterfield DA (2012) Rat Brain Pro-Oxidant Effects of Peripherally Administered 5nm Ceria 30 Days After Exposure. Neurotoxicol. 33:1147-1155.

[18] Hata K, Futaba BN, Mizuno K, Namai T, Yumura M, Iijima I (2004) Water Assisted Highly Efficient Synthesis of Impurity-Free Single-Walled Carbon Nanotubes. Sci. 306(5700):1362-1364.

[19] Iijima S (1991) Helical Microtubules of Graphitic Carbon.Nature 354: 56-58.

[20] Kang S, Pinault M, Pfefferle LD, Elimelech M (2007) Single Walled Carbon Nanotubes Exhibit Strong Antimicrobial Activity. Langmuir 23(17):8670-8673.

[21] Lam CW, James JT, McCluskey R, Hunter RL (2004) Pulmonary Toxicity of Single Walled Carbon Nanotubes in Mice 7 and 90 Days After Intratracheal Instillation. Toxicol Sci. 77:126-134.

[22] LeBlanc AJ, Moseley AM, Chen BT, Frazer D, Castranova V, Nurkiewicz TR (2010) Nanoparticle Inhalation Impairs Coronary Microvascular Reactivity via a Local Reactive Oxygen SpeciesDependent Mechanism. CardiovascToxicol. 10(1):2736.

[23] Li Z, Hulderman T, Salmen R, Chapman R, Leonard SS, Young SH, SHvedova A, Luster MI, Simeonova PP (2007) Cardiovascular Effects of Pilmonary Exposure to Single Wall Carbon Nanotubes. Environ. Health Perspect. 115(3):377-382.

[24] Manna SK, Ramesh GT (2005) Interleukin-8 induces nuclear transcription factor $k$-B through TRAF6dependent pathway. J. Biol. Chem. 280:7010-7021.

[25] Marayuma S, Kojima R, Miyauchi Y, Chiashi S, Kohno M (2002) Low-temperature synthesis of highpurity single-walled carbon nanotubes from alcohol. Chem. Phys.Lett. Elsevier 360(3,4):229-234.

[26] Murray AR, Kisin E, Leonard SS, Young SH, Kommineni C, Kagan VE, Castronova V, Shvedova AA (2009) Oxidative Stress and Inflammatory Response in Dermal Toxicity of Single Walled Carbon Nanotubes. Toxicol. Elsevier 257(3):161-171.
[27] Ong L, Chung FF, Tan Y, Leong C (2016) Toxicity of Single Walled Carbon Nanotubes. Arch. Toxicol. 90(1):103-118. Review.

[28] Pacurari M, Yin XJ, Zhao J, Ding M, Leonard SS, Schwegler-Berry D, Ducatman BS, Sbarra D, Hoover MD, Castranova V, Vallyanthan (2008) Raw SingleWall Carbon Nanotubes Induce Oxidative Stress and Activate MAPKs, AP-1, NF-kB, and Akt in Normal and Malignant Human Mesothelial Cells. Environ.Health Perspect. 116(9):1211-1217.

[29] Poland, Duffin R, Kinloch I, Maynard A, Wallace WAH, Seaton A, Stone V, Brown S, MacNee W, Donaldson K (2008) Carbon nanotubes introduced into the abdominal cavity of mice show asbestos-like pathogenicity in a pilot study. Nature Nanotechnol. 3:423-428.

[30] Poma A, Di Giorgio ML (2008) Toxicogenomics to Improve Comprehension of the Mechanisms Underlying Responses of In Vitro and In Vivo Systems to Nanomaterials: A Review. Curr.Gen. 9:571-585.

[31] Ravichandran P, Baluchamy S, Sadanandan B, Gopikrishnan R, Biradar S, Ramesh V, Hall JC, Ramesh GT (2010) Multiwalled Carbon Nanotubes Activate NF- $k \mathrm{~B}$ and AP-1 Signaling Pathways to Induce Apoptosis in Rat Lung Epithelial Cells. Apoptosis 15:1507-1516.

[32] Saptarshi SR, Duschl A, Lopata AL (2013) Interaction of Nanoparticles with Proteins: Relation to Bio-Reactivity of the Nanoparticle. J. Nanobiotechnol. 11:26.

[33] Sargent LM, Porter DW, Staska LM, Hubbs AF, Lowry DT, Battelli L, Siegrist KJ, Kashon ML, Mercer RR, Bauer AK, Chen BT, Salisbury JL, Frazer D, McKinney W, Andrew M, Tsuruoka S, Endo M, Fluharty KL, Castranova V, Reynolds SH (2014) Promotion of Lung Adenocarcinoma Following Inhalation Exposure to Multi-Walled Carbon Nanotubes. Part. FibreToxicol.11:3.

[34] Sayes CM , Liang F, Hudson JL, Mendez J, Guo W, Beach JM, Moore VC, Doyle CD, West JL, Billups WE, Ausman KD, Colvin VL (2006) Functionalization Density Dependence of SingleWalled Carbon Nanotubes Cytotoxicity In vitro. Toxicol.Lett. 161(2):135-142.

[35] Schipper ML, Nakayama-Ratchford N, Davis CR, Kam NWS, Chu P, Liu Z, Sun X, Dai H, Gambhir SS (2008)A Pilot Toxicology Study of Single-Walled Carbon Nanotubes in a Small Sample of Mice. Nat. Nanotechnol. 3:216 - 221.

[36] Smith CJ, Shaw BJ, Handy RD (2007) Toxicity of Single Walled Carbon Nanotubes to Rainbow Trout, (Oncorhynchusmykiss): Respiratory toxicity, organ pathologies, and other physiological effects. Aquat.Toxicol.Elsevier. 82(2):94-109.

[37] Stimers P (2008) The Implications of Recent Nanomaterials Toxicity Studies for the Nanotech Community. Nanotechnol. Law Bus. 5(3):313-318.

[38] Totsuka Y, Higuchi T, Imai T, Nishikawa A, Nohmi T, Kato T, Masuda S, Kinae N, Hiyoshi K, Ogo S, 
Kawanishi M, Yagi T, Ichinose T, Fukumori N, Watanabe M, Sugimura T, Wakabayashi K (2009)

Genotoxicity of Nano/Microparticles in In vitro Micronuclei, In vivo COMET and Mutation Assay Systems. Part. FibreToxicol. 6:23

[39] Tsuda H (2010) Risk Assessment Studies of Nanomaterials in Japan and Other Countries. Asian Pacific J. Cancer Prev. 11:13-14.

[40] VeenaChoudhary and Anju Gupta (2011). Polymer/Carbon Nanotube Nanocomposites, Carbon Nanotubes - Polymer Nanocomposites, Dr. Siva Yellampalli (Ed.), InTech, DOI: 10.5772/18423.

[41] Wang H, Wang J, Deng X, Sun H, Shi Z, Gu Z, Liu Y, Zhaoc Y (2004) Bio Distribution of Carbon Single Wall Carbon Nanotubes in Mice. J. Nanosci. Nanotechnol. 4:1019-1024.

[42] Warheit DB, Laurence BR, Reed KL, Roach DH, Reynolds GA, Webb TR (2004) Comparative Pulmonary Toxicity Assessment of Single Walled Carbon Nanotubes in Rats. Toxicol Sci. 77:117-125.

[43] Wong BS, Yoong SL, Jagusiak A, Panczyk T, Ho HK, Ang WH, Pastorin G (2013) Carbon Nanotubes for Delivery of Small Molecule Drugs. Adv Drug Deliv Rev. 65(15):1964-2015.

[44] Yang ST, Wang X,Jia G, Gu Y, Wang T, Haiyu N, Ge C, Wang H,Liu Y (2008) Long-term accumulation and low toxicity of single-walled carbon nanotubes in intravenously exposed mice. Toxicol.Lett. 181(3):182-189.

[45] Yang X, Liu J, He H, Zhou L, Gong C, Wang X, Yang L, Yuan J, Huang H, He L, Zhang B, Zhuang Z (2010) $\mathrm{SiO}_{2}$ Nanoparticles Induce Cytotoxicity and Protein Expression Alteration in HaCaT Cells. Part.FibreToxicol.7:1. 